Ioannis Pneumatikos

\title{
Preventing ventilator-associated pneumonia: is it ultimately only a matter of gravity?
}

Received: 19 December 2011

Accepted: 20 December 2011

Published online: 18 February 2012

(C) Copyright jointly held by Springer and ESICM 2012

This editorial refers to the article available at: doi:10.1007/s00134-012-2495-2.

I. Pneumatikos (®)

Department of Intensive Care Medicine,

University Hospital of Alexandroupolis,

68100 Alexandroupoli, Greece

e-mail: ipnevmat@med.duth.gr
Ventilator-associated pneumonia (VAP) is defined as pneumonia that develops $48 \mathrm{~h}$ or longer after initiation of mechanical ventilation via an endotracheal tube (ET). The incidence of VAP is high, ranging from 10 to $30 \%$. VAP is associated with significantly increased morbidity and mortality, hospital length of stay, and costs [1]. Prevention of VAP is therefore one of the foremost aims in mechanically ventilated critically ill patients.

The pathogenesis of VAP usually requires that two important processes take place: bacterial colonization of the aerodigestive tract and the aspiration of contaminated secretions into the lower airway across the ET cuff [2]. Controversy exists on the relevance of bacterial colonization of the stomach and gastroesophageal aspiration in the pathogenesis of VAP [3]. About 20 years ago, experimental studies with radioactive-labeled enteral feeding suggested that endotracheal aspiration of gastric contents occurred more frequently when patients were placed in the supine rather than semirecumbent position [4]. Thus, placing a patient in the semirecumbent position-with the head elevated at a $30-45^{\circ}$ positionseemed a logical solution to prevent VAP.
Nowadays, the semirecumbent position is considered one of the most effective, easy to implement, and inexpensive methods for the prevention of VAP in mechanically ventilated patients in the ICU. For this reason it has been widely adopted not only in practice guidelines but, recently, in most of the care bundles aimed at preventing VAP [5, 6]. Surprisingly, data supporting the effectiveness of the semirecumbent position are relatively few and conflicting, resulting only from three, rather small, randomized controlled trials [7-9]. Moreover, this intervention has an important drawback: The feasibility of a $45^{\circ}$ bed orientation in ICUs is debated because it depends on nursing tasks, medical interventions, and the patient's wishes [10]. Apart from this disadvantage, the semirecumbent position has also been implicated in some complications such as venous stasis in the lower extremities with the risk of venous thromboembolism, caudal shift of blood with the risk of hemodynamic instability, and the risk of bed sores [11]. Hence, no clear conclusions about the effect of the semirecumbent position on VAP prophylaxis can be drawn.

In this issue of Intensive Care Medicine Zanella et al. [12] examine the incidence of VAP in swine placed in a prone position with the orientation of trachea and ET above horizontal $\left(\right.$ at $45^{\circ}$ ) and below horizontal $\left(\right.$ at $-10^{\circ}$ ). Pigs were randomized into four groups and ventilated for $72-168 \mathrm{~h}$ with and without enteral feeding. At the end of the study period, all pigs were killed and the clinical diagnosis of VAP was microbiologically evaluated. This long-term study, as Zanella et al. note, aimed to model some of the determinants of VAP: intubation, deep sedation, mechanical ventilation, and enteral feeding. Their findings were really impressive! All pigs kept oriented with trachea $45^{\circ}$ above horizontal developed VAP. In contrast, none of the pigs kept oriented with the trachea below horizontal developed VAP. Here, we must emphasize that the above animal model is one of the most 
reliable for studying the pathogenesis of VAP for two reasons: first, because it is directly related to the common pathophysiological mechanisms of VAP in which colonization and microaspiration to the lower airways are the main steps; and second, because in this model the incidence of VAP approaches 100\% [13].

The study by Zanella et al. supports previous laboratory findings indicating no altered airway colonization and excellent gas exchange and lung function after horizontal orientation of the ET and neck of the animals, through a lateral body rotation [14]. Moreover, another randomized animal study by Li Bassi et al. [15] showed that following tracheal intubation, gravitational force influences tracheal mucus clearance. When the trachea is above horizontal, a flow of mucus from the proximal trachea toward the lungs is highly associated with bacterial colonization of the airways and pneumonia. In contrast, keeping the ET and trachea even slightly below horizontal meant that mucus always moved toward the glottis and lung remained free from bacterial colonization [15].

Recently, Mauri et al. [16], going a step further, showed for the first time that the lateral-horizontal position (similar to the recovery position in basic life support) implemented for $12-24 \mathrm{~h}$ in 10 adult intubated ICU patients is feasible and without adverse events. Interestingly, the incidence of aspiration of gastric contents in this lateral-horizontal position was shown to be similar to that in the semirecumbent position. Unfortunately, the pepsin they used as a marker of gastric contents is not designed to discriminate various magnitudes of airway contamination by gastric contents. Taken together, all the above data indicate that the horizontal-lateral position probably has major advantages compared with the semirecumbent position.

How, therefore, can these experimental data translated into clinical practice? Undoubtedly, the proper body position may play an important role in VAP prevention. In particular, maintaining the direction of ET/oropharynx/ trachea axis of mechanically ventilated patients below horizontal in a slight Trendelenburg position can both hinder microaspiration of oropharyngeal secretions along the longitudinal folds of the cuff and enhance mucus drainage. However, the effectiveness of this intervention should be documented by the results of well-designed randomized controlled trials in humans. These studies should also consider very carefully whether it is feasible in daily practice to keep patients in the same body position, because any change, even short, may favor pulmonary aspiration. This is what the experience of maintaining patients in the semirecumbent position has shown [10]. A final comment regarding the safety of the lateral slight Trendelenburg position: In patients with severe closed head injury this body position can lead to a catastrophic increase in intracranial pressure [17]!

\section{References}

1. Safdar N, Dezfulian C, Collard HR, Saint S (2005) Clinical and economic consequences of ventilator-associated pneumonia: a systematic review. Crit Care Med 33:2184-2193

2. Kollef MH (1999) The prevention of ventilator associated pneumonia. N Engl J Med 340(8):627-634

3. Bonten MJ, Gaillard CA, de Leeuw PW, Stobberingh EE (1997) Role of colonization of the upper intestinal tract in the pathogenesis of ventilator associated pneumonia. Clin Infect Dis 24(3):309-319

4. Torres A, Serra-Batlles J, Ros E, Piera C, Puig de la Bellacasa J, Cobos A, Lomena F, Rodriguez-Roisin R (1992) Pulmonary aspiration of gastric contents in patients receiving mechanical ventilation: the effect of body position. Ann Intern Med 116:540-543

5. American Thoracic Society, Infectious Diseases Society of America (2005) Guidelines for the management of adults with hospital-acquired, ventilator-associated, and healthcareassociated pneumoni. Am J Respir Crit Care Med 171:388-416
6. Hawe CS, Ellis KS, Cairns CJ, Longmate A (2009) Reduction of ventilator-associated pneumonia active versus passive guideline implementation. Intensive Care Med 35:1180-1186

7. Drakulovic MB, Torres A, Bauer TT, Nicolas JM, Nogue S, Ferrer M (1999) Supine body position as a risk factor for nosocomial pneumonia in mechanically ventilated patients: a randomised trial. Lancet 354:1851-1858

8. Keeley L (2007) Reducing the risk of ventilator-acquired pneumonia through head of bed elevation. Nurs Crit Care 12:287-294

9. van Nieuwenhoven CA, Vandenbroucke-Grauls C, van Tiel FH, Joore HC, van Schijndel RJ, van der Tweel I, Ramsay G, Bonten MJ (2006) Feasibility and effects of the semirecumbent position to prevent ventilator-associated pneumonia: a randomized study. Crit Care Med 34:396-402

10. Combes A (2006) Backrest elevation for the prevention of ventilatorassociated pneumonia: back to the real world? Crit Care Med 34:559-561
11. Niël-Weise BS, Gastmeier P, Kola A, Vonberg RP, Wille JC, Van den Broek PJ, Head Bed Elevation Study Group (2011) An evidence-based recommendation on bed head elevation for mechanically ventilated patients. Crit Care 15:R111

12. Zanella A, Cressoni M, Epp M, Hoffmann V, Stylianou M (2012) The effects of tracheal orientation on the development of ventilator associated pneumonia: an experimental study. Intensive Care Med. doi: 10.1007/s00134-012-2495-2

13. Marquette $\mathrm{CH}$, Wermert $\mathrm{D}$, Wallet $\mathrm{F}$, Copin MC, Tonnel AB (1996)

Characterization of an animal model of ventilator associated pneumonia. Chest 115:200-209

14. Panigada M, Berra L, Greco G, Stylianou M, Kolobow T (2003) Bacterial colonization of the respiratory tract following tracheal intubationeffect of gravity: an experimental study. Crit Care Med 31:729-737 
15. Li Bassi G, Zanella A, Cressoni M, Stylianou M, Kolobow T (2008)

Following tracheal intubation, mucus

flow is reversed in the semirecumbent position: possible role in the pathogenesis of ventilator-associated pneumonia. Crit Care Med 36:518-525
16. Mauri T, Berra L, Kumwilaisak K, Pivi S, Ufberg JW, Kueppers F, Pesenti A, Bigatello LM (2010) Lateral-horizontal patient position and horizontal orientation of the endotracheal tube to prevent aspiration in adult surgical intensive care unit patients: a feasibility study. Respir Care 55:294-302
17. Agbeko RS, Pearson S, Peters MJ, McNames J, Goldstein B (2011) Intracranial pressure and cerebral perfusion pressure responses to head elevation changes in pediatric traumatic brain injury. Pediatr Crit Care Med. doi: 10.1097/PCC.0b013e31820ac2ad 